\title{
Erosion-Corrosion Resistance and Electrochemical Behavior of AZ31 Magnesium Alloy Processed by Equal Channel Angular Pressing (ECAP)
}

\author{
Osama M. Irfan ${ }^{1,2}$ \\ ${ }^{1}$ Departments of Mechanical Engineering, Qassim University, Saudi Arabia \\ ${ }^{2}$ Department of Mechanical Engineering, Beni Suef University, Egypt \\ E-mail: osamaerfan@qec.edu.sa
}

doi: $10.20964 / 2021.04 .25$

Received: 2 December 2020 / Accepted: 19 January 2021 / Published: 28 February 2021

The current work studies the effect of Equal Channel Angular Pressing (ECAP) on the erosion corrosion (E-C) resistance and electrochemical behavior of Magnesium AZ31 Alloy. Samples of AZ31 alloy were subjected to ECAP process up to four passes at $200^{\circ} \mathrm{C}$. The Vickers micro hardness, $\mathrm{Hv}$ had been measured and the structural homogeneity was assessed. Microstructural images by optical microscopy were evaluated. The E-C tests by slurry pot method through weight loss and electrochemical analysis had been conducted. Simulated sea water with silica sand particles was used in the E-C experiments. Scanning electron microscope SEM was employed to investigate the samples after E-C. The potentiodynamic polarization was achieved from a simulated sea water solution $(3.5 \% \mathrm{NaCl})$ and electrochemical impedance spectroscopy was carried out on the solution to examine the surface properties of the samples. The effects of flow velocity and testing time on the weight loss due to E-C at different ECAP passes were investigated. The results indicated an increase in hardness after four ECAP passes with substantial structural homogeneity. For all velocities, the weight loss of samples subjected to ECAP is lower compared to the original samples. It is obvious that the time has a serious effect on the E-C resistance of AZ31 alloy. For samples subjected to ECAP, time has less influence on material removal.

Keywords: AZ31 magnesium alloy; ECAP; Erosion-corrosion; Electrochemical

\section{$\underline{\text { FULL TEXT }}$}

(C) 2021 The Authors. Published by ESG (www.electrochemsci.org). This article is an open access article distributed under the terms and conditions of the Creative Commons Attribution license (http://creativecommons.org/licenses/by/4.0/). 
Int. J. Electrochem. Sci., 16 (2021) Article ID: 21047 